\title{
Chromosome number, microsporogenesis, microgametogenesis, and pollen viability in the Brazilian native grass Mesosetum chaseae (Poaceae)
}

\author{
L.A.C. Silva ${ }^{1}$, M.S. Pagliarini ${ }^{1}$, S.A. Santos ${ }^{2}$, N. Silva ${ }^{1}$ and V.F. Souza ${ }^{1}$ \\ ${ }^{1}$ Departamento de Biologia Celular e Genética, \\ Universidade Estadual de Maringá, Maringá, PR, Brasil \\ ${ }^{2}$ Embrapa Pantanal, Corumbá, MS, Brasil \\ Corresponding author: M.S. Pagliarini \\ E-mail: mspagliarini@uem.br
}

Genet. Mol. Res. 11 (4): 4100-4109 (2012)

Received March 22, 2012

Accepted May 21, 2012

Published September 12, 2012

DOI http://dx.doi.org/10.4238/2012.September.12.1

\begin{abstract}
The genus Mesosetum is a primarily South American genus with 42 species. Mesosetum chaseae, regionally known as 'grama-do-cerrado', is abundant in the Pantanal Matogrossense (Brazil); it is a valuable resource for livestock and for environmental conservation. We collected specimens from the Nhecolandia subregion of the Brazilian Pantanal, located in Corumbá, Mato Grosso do Sul, Brazil. We examined chromosome number, ploidy level, meiotic behavior, microgametogenesis, and pollen viability of 10 accessions. All the accessions were diploid, derived from $\mathrm{x}=8$, presenting $2 \mathrm{n}$ $=2 \mathrm{x}=16$ chromosomes. Chromosomes paired as bivalents showing, predominantly, two terminal chiasmata. Interstitial chiasmata were rare. Meiosis was quite normal producing only a few abnormal tetrads in some accessions. Microgametogenesis, after two mitotic divisions, produced three-celled pollen grains. Pollen viability was variable
\end{abstract}


among plant and accessions and was not correlated with meiotic abnormalities.

Key words: Mesosetum chaseae; 'Grama-do-cerrado'; Meiosis; Chromosome number; Microgametogenesis; Pollen viability

\section{INTRODUCTION}

The genus Mesosetum was described by Steudel in 1854, based on a single species, Mesosetum cayennense. For more than 50 years, the genus remained unrecognized. This genus belongs to the tribe Paniceae in the group with Erichloa, Brachiaria, Axonopus, Centrichloa, Echinolaena, and Pseudoechinolena, in which the back of the fruit is turned away from the rachis. It differs from all of these in having a slender solitary raceme, with the fruit of the solitary spikelet usually swollen on the side toward the rachis rather than on the side away from it, as in the related genera (Swallen, 1937).

The genus Mesosetum is organized into finer groupings including 42 species. M. chaseae Luces is a perennial species with elongated rhizomes and stolons; erect culms, 25-65 $\mathrm{cm}$ long; inflorescences composed of a single unilateral raceme, 3-9 cm long; solitary spikelets with a basal sterile floret (male) and a fertile floret: flowers with 3 purple anthers, and fruit as caryopsis. More morphological details can be found at http//www.kew.org/data/grasses$\mathrm{db}$. Mesosetum is primarily a South American genus. The largest number of species occurs on the open sandy savannas of northeastern Brazil (Swallen, 1937). M. chaseae, a native of the wetland Pantanal, has great economic and environmental importance in the Nhecolandia and Paiaguas sub-regions. This species, known as 'grama-do-cerrado', is highly tolerant to drought and poor soil (Santos et al., 2004) and is highly palatable to cattle in dry periods (Santos et al., 2002).

Chromosome numbers have proved to be of great value in understanding the evolution of vascular plants (Raven, 1975; Sede et al., 2010), particularly with regard to rate of polyploidy (Davidse et al., 1986). Although polyploidy is a common feature in the Poaceae, karyological studies are still lacking in many tropical and subtropical grasses (Sede et al., 2010), thus limiting our ability to understand the patterns of chromosome change across the family.

M. chaseae had not been cytologically studied. Thus, the purpose of this study is to provide some cytological knowledge about it as a subsidy for conservation and future breeding programs. Here, we describe chromosome number, levels of ploidy, meiotic behavior, microgametogenesis, and pollen viability for 10 accessions of this species available in the germplasm collection at Embrapa Pantanal (MS, Brazil).

\section{MATERIAL AND METHODS}

\section{Material}

The accessions of $M$. chaseae analyzed were collected from various locations in the Nhecolandia sub-region (Pantanal), and constitute part of the germplasm collection at Embrapa Pantanal (Nhumirin Farm, Nhecolandia sub-region, Pantanal, Corumbá, Mato Grosso do 
Sul, Brazil). Table 1 indicates the places of collection according to the Universal Transverse Mercator (UTM) system.

Table 1. Number of accessions in the germplasm collection, place of collection, landscape unit, and collection
point (UTM).
\begin{tabular}{llll}
\hline Accession & Place of collection & Phytophysionomy & UTM \\
\hline 1 & Nhumirim Farm & Non-flooding open grassland & $540089 / 7898986$ \\
2 & Nhumirim Farm & Flooding open grassland & $538171 / 7897724$ \\
3 & Nhumirim Farm & Non-flooding open grassland & $535406 / 7899592$ \\
4 & Campo Dora Farm & Flooding open grassland & $533485 / 7901107$ \\
5 & Chatelodo Farm & Non-flooding open grassland & $534401 / 7890612$ \\
6 & Chatelodo Farm & Non-flooding open grassland & $534641 / 7893824$ \\
7 & Chatelodo Farm & Non-flooding Savanna & $534754 / 7895118$ \\
8 & Valdir's Field Farm & Non-flooding Savanna & $540493 / 7906116$ \\
9 & Valdir's Field Farm & Babacu's Forest edge & $540452 / 7906193$ \\
24 & Nhumirim Farm & Non-flooding open grassland & $539319 / 7902$ \\
\hline
\end{tabular}

$\mathrm{UTM}=$ Universal Transverse Mercator Projection.

\section{Chromosome number, meiotic behavior, and microgametogenesis}

Inflorescences in the appropriate stage for meiotic studies were collected from the field during the morning hours. The inflorescences were fixed in a mixture of ethanol-acetic acid $(3: 1, \mathrm{v} / \mathrm{v})$ for $24 \mathrm{~h}$, and then stored under refrigeration in $70 \%$ ethanol. Meiocytes were obtained by squashing anthers in a drop of $1 \%$ propionic-carmine. Chromosome number was counted in 20 meiocytes at diakinesis. All meiotic phases were evaluated under light microscopy and meiotic abnormalities were scored. Microgametogenesis was evaluated in apical mature flowers of the racemes fixed for meiotic studies. Photomicrographs were taken using a Wild Leitz microscope with Kodak Imagelink-HQ, ISO 25 black and white film.

\section{Pollen viability}

Inflorescences at anthesis were collected, fixed in $70 \%$ alcohol, and stored under refrigeration until analysis. Pollen grains were released from the anthers and differentially stained with $2 \%$ lugol, $1 \%$ propionic carmine, and Safrablau. For each accession, 10 flowers of 10 inflorescences were tested. Ten slides for each staining were prepared, and in each slide, a total of 100 pollen grains were analyzed at random. The analyses were developed under light microscopy with $400 \mathrm{X}$ magnification. Pollen grains with abnormal size, weak staining, or reduced or absent cytoplasm were considered to be sterile, and those well stained, as viable.

\section{RESULTS AND DISCUSSION}

\section{Chromosome number}

The accessions of $M$. chaseae analyzed presented $2 \mathrm{n}=16$ chromosomes (Figure 1). Although only a few cytological studies have been developed for the genus Mesosetum, 
it has been suggested that the base chromosome number is $\mathrm{x}=8$ (Gould, 1966; Gould and Soderstrom, 1967; Pohl and Davidse, 1971; Davidse and Pohl, 1972). A chromosome count of $2 \mathrm{n}=16$ had been reported for M. pittieri (Gould, 1966) and a count of $2 \mathrm{n}=32$ had been reported for M. lolliforme (Gould and Soderstrom, 1967; Sede et al., 2010).

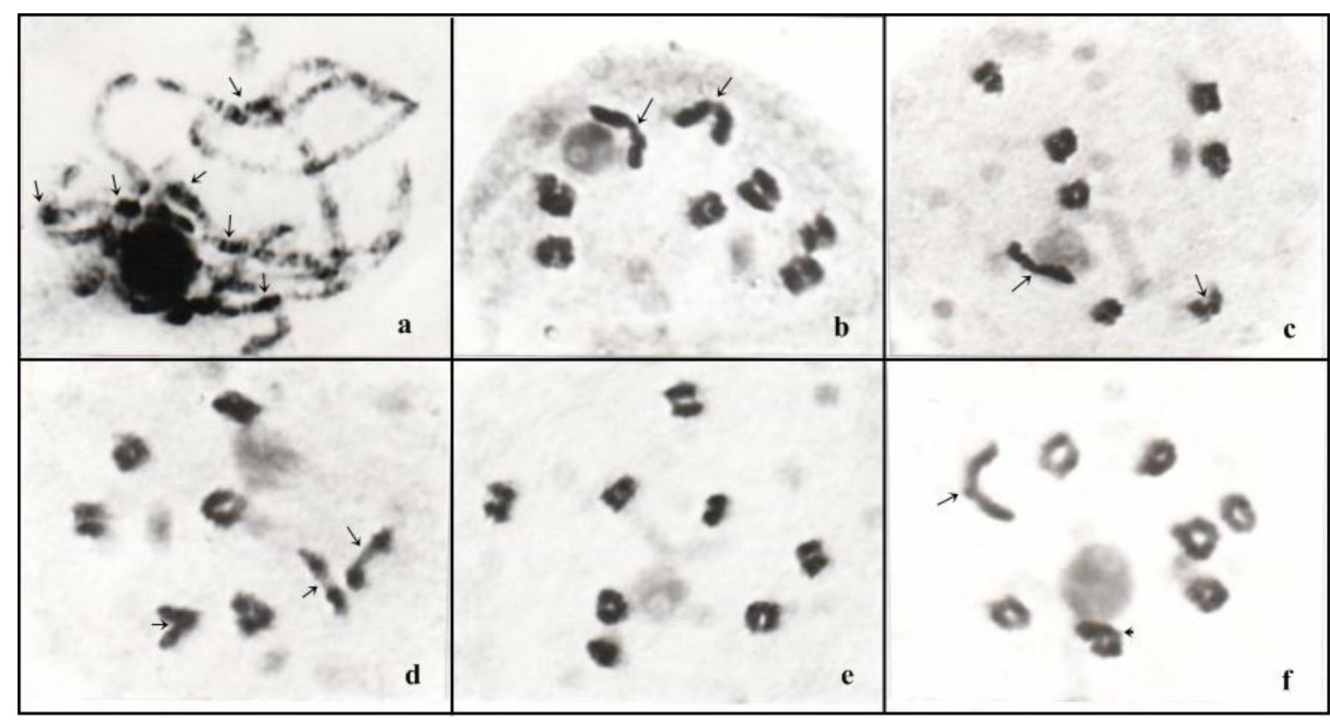

Figure 1. Aspects of chromosome behavior at prophase I in Mesosetum chaseae. a. Meiocyte at pachytene showing paired chromosomes with dense heterochromatic regions (arrows). b. f. Diakinesis with eight bivalents. b. c. Diakinesis with two bivalents with one terminal chiasma (arrows) and six bivalents with two terminal chiasmata. d. Diakinesis with three bivalents with one terminal chiasma (arrows). e. Diakinesis with eight bivalents with two terminal chiasmata. f. Diakinesis with one bivalent with one terminal chiasma (arrow), one bivalent with three chiasmata (arrowhead) and six bivalents with two terminal chiasmata.

According to Hunziker and Stebbins (1986), the original basic chromosome number for Poaceae has been the subject of much speculation. In their opinion, the original basic number appears to be $\mathrm{x}=6$ and on this basis tetraploid levels are quite frequent. From $\mathrm{x}=$ 6 aneuploid increase and reduction probably gave $\mathrm{x}=7$ and 5, respectively; from the latter came secondary $\mathrm{x}=10$, and from $\mathrm{x}=12$ originated $\mathrm{x}=11,10,9,8$, and again 7 . The basic number $\mathrm{x}=8$, as found in $M$. chaseae, is extremely rare in the family Poaceae (Stebbins, $1982,1985)$.

Although chromosomes were not measured in M. chaseae, they appeared to be large and presenting several heterochromatic regions, probably corresponding to chromomeres (Figure 1a) when compared to other members of Poaceae (for example, Brachiaria, Paspalum, and Panicum). According to Hunziker and Stebbins (1986), chromosome size varies tremendously in the Poaceae family, ranging from $0.60 \mu \mathrm{M}$ in Bambusoideae to almost 10 $\mu \mathrm{M}$ in Secale. The variation in size and basic numbers among the various taxonomic subdivisions emphasizes the enormous biological diversity within the family. 


\section{Microsporogenesis}

The studies of microsporogenesis in $M$. chaseae demonstrated data compatible with diploidy $(2 \mathrm{n}=2 \mathrm{x}=16)$. Chromosome association at prophase I was exclusively in bivalents (Figure $1 \mathrm{~b}$ and $\mathrm{f}$ ). Two terminal chiasmata occurred predominantly among bivalents. Three chiasmata per bivalent and interstitial chiasma were rare. The genetic variability of a population results from the action of a series of genetically controlled factors (Grant, 1958). Among these factors, genetic recombination, which involves chromatin exchange between homologous chromosomes, is particularly significant. The sites of genetic exchange are cytologically visible as crosses between the arms of chromosomes and are termed as 'chiasmata'. Thus, the chiasma frequency is usually considered a good estimate of the level of genetic recombination in a population. However, when chiasmata are strictly terminal, the organism is effectively free from recombination even though the frequency of chiasmata is high (Sybenga, 1972). According to Stebbins (1971), this type of chiasma also reduces recombination by keeping genes that interact to produce characteristics of particular high adaptive value together. In the case of $M$. chaseae, terminal chiasmata probably preserve some chromosome regions responsible for the adaptation to the extreme environmental conditions in the Pantanal.

In M. chaseae, the meiotic behavior was quite normal. Only a few meiotic abnormalities were detected among meiocytes, mainly in the first division (Table 2). The more frequent abnormalities were those related to irregular chromosome segregation, such as precocious chromosome migration to the poles in metaphase I and metaphase II (Figure 2e and f), and laggard chromosomes in anaphase I (Figure 2a and c) and anaphase II. These abnormalities led to micronucleus formation in telophase I (Figure 2d) and telophase II (Figure 2g), which remained in the microspores of the tetrad (Figure $2 \mathrm{~h}$ ). In rare cases, the micronuclei of the tetrad were isolated by cytokinesis, generating polyads (Figure 2i). These abnormalities could arise from precocious chiasma terminalization since terminal chiasmata predominated. The frequency of abnormalities in the second division was very low, producing a high number of normal tetrads.

\section{Microgametogenesis}

In all the accessions of $M$. chaseae, the microgametogenesis followed the pattern recognized for members of Poaceae (Maheshwari, 1978; Bedinger, 1992; McCormick, 1993; Shivanna, 2003). Soon after their release from the tetrads, microspores expand rapidly and became spherical, showing a large central nucleus (Figure 3a and b). In the next phase, entering mitosis, the microspore nucleus was allocated to a peripheral position (Figure 3c), creating asymmetry, and the next steps of mitosis occurred and were well visualized as prophase (Figure $3 \mathrm{c}$ and $\mathrm{d}$ ), metaphase (Figure $3 \mathrm{e}$ and $\mathrm{g}$ ), anaphase (Figure $3 \mathrm{~h}$ ), and telophase (Figure 3i). The microspore mitosis gives rise to a pollen grain containing vegetative (large) and generative (small) cells (Figure 3j). Following this phase, the generative cell entered mitosis (Figure $3 \mathrm{k}$ and $\mathrm{l}$ ), generating a 3 -celled pollen grain (Figure $3 \mathrm{~m}$ ). Viable pollen grains developed a large number of plastids (Figure $3 \mathrm{n}$ and $\mathrm{p}$ ). Plastids are frequently present in the pollen grain of grasses (Mogensen, 1990; Dafni, 1992; Shivanna, 2003). 


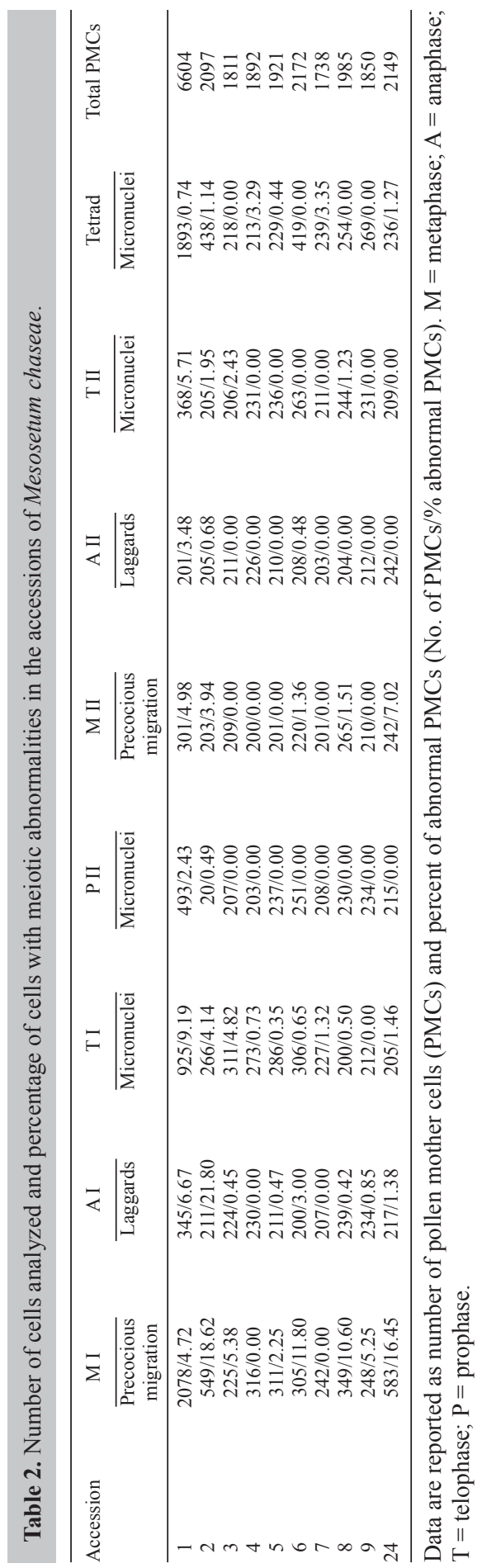




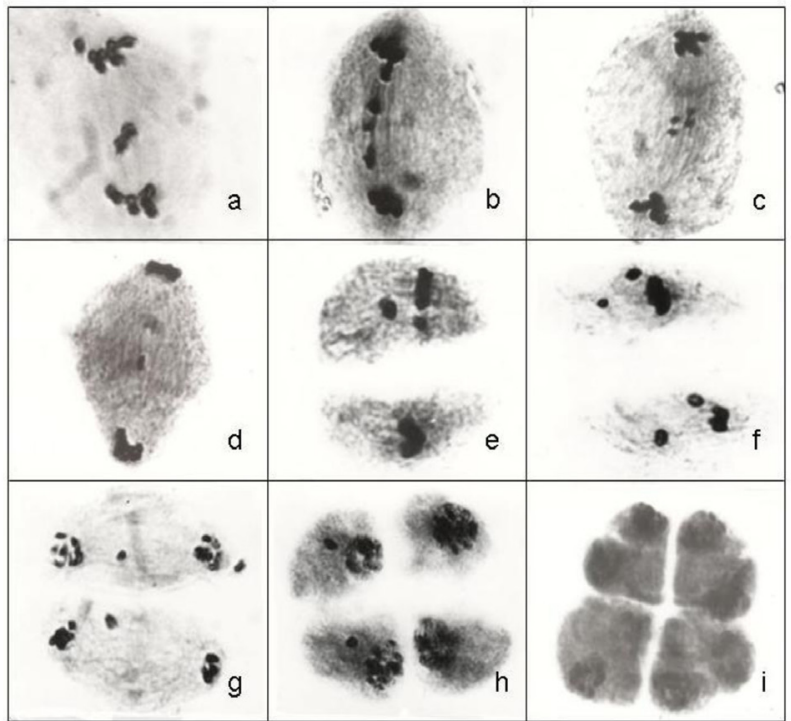

Figure 2. Meiotic behavior in the Mesosetum chaseae accessions. a. b. c. Meiocytes in anaphase I with laggard chromosomes. d. Telophase I with central micronuclei. e. f. Metaphase II with precocious chromosome migration to the poles. g. Telophase II with micronuclei. h. Tetrad with micronucleus in two microspores. i. Polyad.

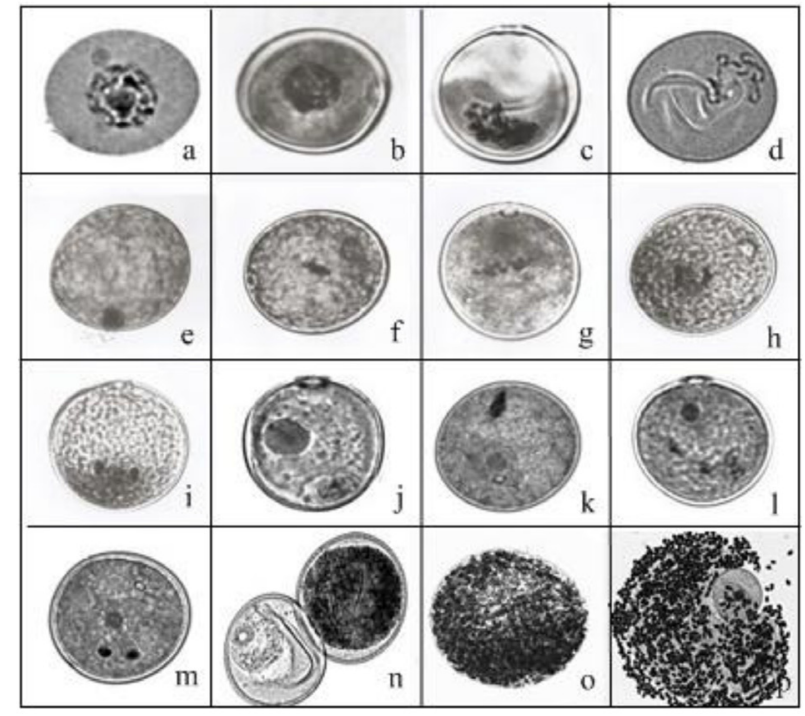

Figure 3. Microgametogenesis in Mesosetum chaseae. a. Microspore released from the tetrad with a central nucleus. b. Early prophase in the microspore. c. Asymetric prophase. Note the position of nucleus in relation to the pore. d. Late prophase. e. f. g. Metaphase. Note the eight chromosomes in the metaphase plate. h. Anaphase. i. Telophase. j. Pollen grain. Note the presence of the vegetative and the generative cells and the well-developed pollen membrane. k. Metaphase in the generative cell of the pollen grain. l. Anaphase in the generative cell. $\mathbf{m}$. 3-celled pollen grain, i.e., two sperm cells and one vegetative cell. n. Fertile (dark) and sterile pollen grains. o. Fertile pollen grain with plastids. p. Pollen grain stained with lugol showing a dozen of plastids. 


\section{Pollen viability}

Pollen viability refers to the ability of the pollen to perform its function of delivering male gametes to the embryo sac (Shivanna, 2003). According to Dafni (1992), assessment of pollen viability can be used for 1) evaluation of the fertility of a given parental plant, particularly in breeding programs; 2) monitoring the pollen state as a function of storage conditions; 3 ) evaluation of the likelihood of pollen germination in studies of pollen-stigma interaction; 4) studies of incompatibility and fertility; 5) spotting individual hybrids in wild populations; 6) evaluation of the chances of pollen germination after exposure to various conditions, etc. A number of tests have been developed over the years to test pollen viability. Because of the limitations of some original methods, many alternative methods that are simple, convenient, and rapid have been disseminated. Several staining tests use non-vital stain contents of the pollen (Shivanna, 2003). Although these tests are satisfactory for assessing pollen sterility, they cannot confirm pollen viability (Heslop-Harrison et al., 1984).

Table 3 presents the pollen viability data for 3 non-vital stainings of the 10 accessions of $M$. chaseae. There was variation in pollen viability among the accessions. Accession 7 presented the least pollen viability, and accession 9 the greatest. In each accession, pollen viability was similar among the 3 staining tests, indicating that all of them can be used for this purpose. However, considering the ease of use, we recommend lugol for a rapid screening of pollen viability. The standard error of mean, with high values in some accessions, and repetitive for all staining, shows that there is variation in pollen viability among flowers. Figure 4 shows viable and sterile pollen grains differentiated by the 3 stains.

Table 3. Pollen viability and standard error of mean for the three different staining in Mesosetum chaseae.

\begin{tabular}{llrr}
\hline Accession & \multicolumn{3}{c}{ Pollen viability (mean \%) } \\
\cline { 2 - 4 } & Lugol 2\% & Propionic carmine 1\% & Safrablau \\
\hline 1 & $86.8 \pm 12.0$ & $89.4 \pm 8.3$ & $78.1 \pm 10.1$ \\
2 & $77.6 \pm 18.8$ & $77.8 \pm 16.3$ & $75.4 \pm 18.9$ \\
3 & $75.8 \pm 28.2$ & $62.6 \pm 39.4$ & $72.7 \pm 31.5$ \\
4 & $63.3 \pm 31.0$ & $69.9 \pm 17.7$ & $65.3 \pm 31.1$ \\
5 & $76.9 \pm 15.2$ & $76.1 \pm 12.8$ & $73.4 \pm 24.7$ \\
6 & $87.6 \pm 12.6$ & $79.4 \pm 15.2$ & $91.3 \pm 6.1$ \\
7 & $58.6 \pm 38.7$ & $66.9 \pm 31.5$ & $64.7 \pm 33.0$ \\
8 & $81.2 \pm 12.8$ & $85.4 \pm 25.6$ & $83.5 \pm 9.4$ \\
9 & $94.6 \pm 4.4$ & $93.1 \pm 5.9$ & $95.5 \pm 4.1$ \\
24 & $83.2 \pm 8.9$ & $86.2 \pm 10.0$ & $84.5 \pm 10.9$ \\
\hline
\end{tabular}

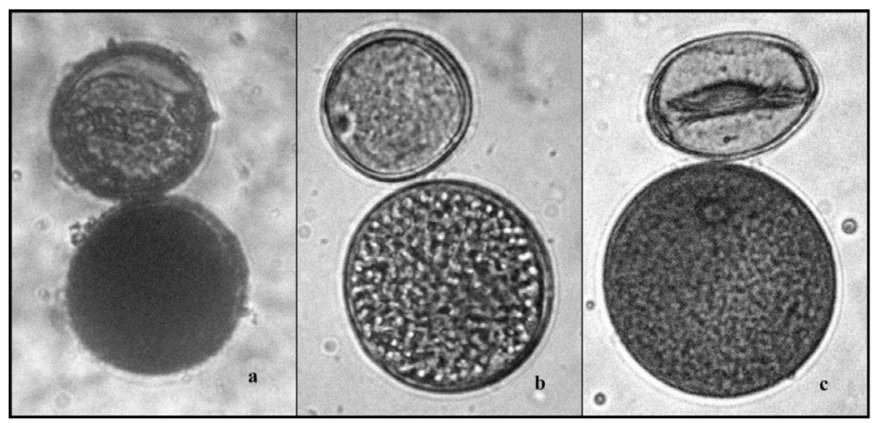

Figure 4. Viable (dark) and sterile pollen grains differentiated by the three staining. a. Lugol. b. Propionic carmine. c. Safrablau. 
Meiotic abnormalities like those observed in the accessions of M. chaseae may cause pollen sterility by affecting the genetic balance of microspores. The influence of meiotic abnormalities on pollen viability has been reported in several species of higher plants (Pagliarini, 2000; Singh, 2003). However, in M. chaseae, there was no correlation between meiotic abnormalities and pollen viability. Accession 4 from flooding open grasslands on sandy soils, for example, presented normal meiosis but showed lower pollen viability. After release, pollen grains are exposed to the environmental conditions. Shivanna (2003) listed several factors that can affect pollen viability. The rapid loss of viability in pollen grains of Poaceae is associated with an inability to withstand desiccation. Pollen grains of Poaceae are shed under hydrated conditions (moisture level of 50\%), and loss of moisture is detrimental to their viability.

Another factor that can affect pollen viability in M. chaseae is that the pollen is 3-celled. Comparative studies carried out on 2- and 3-celled pollen (Johri and Shivanna, 1977; Hoekstra, 1979) have demonstrated a broad correlation between the cytology and viability of pollens. Two-celled pollen grains, in general, retain viability for a longer period than 3-celled pollens. Studies have shown that the rate of respiration in 3-celled pollen is 2-3 times higher than in 2-celled pollen (Hoekstra and Bruinsma, 1975). The authors also found that high temperatures increased the rate of respiration in both 2- and 3-celled pollen, but more so in 3 -celled pollen. These results suggest that pollen viability in $M$. chaseae could be affected by the high temperatures found in the Pantanal Matogrossense, compounded by drought during the period of pollen collection.

The present study, showing that M. chaseae is a diploid species with a very stable meiosis, indicates that breeding programs could be easily performed. Although pollen viability proved to be variable among plants and accessions, it can still be considered sufficient for breeding purposes because the amount of pollen per plant is high.

\section{ACKNOWLEDGMENTS}

Research supported by CNPq and Fundação Araucária.

\section{REFERENCES}

Bedinger P (1992). The remarkable biology of pollen. Plant Cell 4: 879-887.

Dafni A (1992). Pollination Ecology: A Practical Approach. Oxford University Press, Oxford, 249.

Davidse G and Pohl RW (1972). Chromosome numbers, meiotic behavior and notes on some grasses from Central America and the West Indies. Can. J. Bot. 50: 1441-1452.

Davidse G, Hoshino T and Simon BK (1986). Chromosome counts of Zimbabwean grasses (Poaceae) and an analysis of polyploidy in the grass flora of Zimbabwe. South Afr. J. Bot. 52: 521-528.

Gould FW (1966). Chromosome numbers of some Mexican grasses. Can. J. Bot. 44: 1683-1696.

Gould FW and Soderstrom TR (1967). Chromosome numbers of tropical American species. Am. J. Bot. 54: 676-683.

Grant V (1958). The regulation of recombination in plants. Cold Spring Harbor Symp. Quant. Biol. 23: 337-363.

Heslop-Harrison J, Heslop-Harrison Y and Shivanna KR (1984). The evaluation of pollen quality and a further appraisal of the fluorochromatic (FCR) test procedure. Theor. Appl. Genet. 67: 367-375.

Hoekstra FA (1979). Mitochondrial development and activity of binucleate and trinucleate pollen during germination in vitro. Planta 145: 25-36.

Hoekstra FA and Bruinsma J (1975). Respiration and vitality of binucleate and trinucleate pollen. Physiol. Plant. 34: 221-225.

Hunziker JH and Stebbins GL (1986). Chromosomal Evolution in the Gramineae. In: Grass: Systematics and Evolution (Soderstrom TR, Hilu KW, Campbell CS and Barkworth ME, eds.). Smithsonian Institution Press, Washington, 179-187. 
Johri BM and Shivanna KR (1977). Physiology of 2- and 3-celled pollen. Phytomorphology 27: 98-106.

Maheshwari P (1978). An Introduction to the Embriology of Angiosperms. McGraw-Hill Book Company, New York, 453. McCormick A (1993). Male gametophyte development. Plant Cell 5: 1265-1275.

Mogensen HL (1990). Fertilization and Early Embriogenesis. In: Reproductive Versatility in the Grass (Chapman GP, ed.). Cambridge University Press, Cambridge, 76-99.

Pagliarini MS (2000). Meiotic behavior of economically important plant species: the relationship between fertility and male sterility. Genet. Mol. Biol. 23: 997-1002.

Pohl RW and Davidse G (1971). Chromosome numbers of Costa Rican grasses. Brittonia 23: 293-324.

Raven PH (1975). The bases of angiosperm phylogeny: cytology. Ann. Miss. Bot. Gard. 62: 724-764.

Santos AS, Costa C and Souza GS (2002). Composição botânica da dieta de bovinos criados em pastagens nativas na subregião da Nhecolândia, Pantanal, Brasil. Rev. Bras. Zootec. 31: 1648-1662.

Santos AS, Abreu UGP, Comastri Filho JA and Crispim SMA (2004). Recursos Genéticos de Gramíneas Forrageiras para a Pecuária. In: Reunião Anual da Sociedade Brasileira de Zootecnia, SBZ/UCDB, Campo Grande, 17-22.

Sede S, Escobar A, Morrone O and Zuloaga FO (2010). Chromosome studies in American Paniceae (Poaceae, Panicoideae). Ann. Miss. Bot. Gard. 97: 128-138.

Shivanna KR (2003). Pollen Biology and Technology. Science Publishers, Enfield.

Singh RJ (2003). Plant Cytogenetics. 2nd edn. CRC Press, Boca Raton, London.

Stebbins GL (1971). Chromosome Evolution in Higher Plants. Edward Arnold Ltd., London.

Stebbins GL (1982). Major Trends of Evolution in the Poaceae and their Possible Significance. In: Grasses and Grasslands: Systematics and Ecology (Estes JR, Tyrl RJ and Brunken JN, eds.). University of Oklahoma Press, Norman, 3-36.

Stebbins GL (1985). Polyploidy, hybridization and the invasion of new habitats. Ann. Miss. Bot. Gard. 72: 824-832.

Swallen JR (1937). The grass genus Mesosetum. Brittonia 2: 363-392.

Sybenga J (1972). General Cytogenetics. North-Holland Publishing Company, Amsterdam. 